\title{
Opioid use prior to knee arthroplasty in patients who catastrophize about their pain: preoperative data from a multisite randomized clinical trial
}

This article was published in the following Dove Press journal: Journal of Pain Research

\author{
Daniel L Riddle' \\ James D Slover ${ }^{2}$ \\ Dennis C Ang ${ }^{3}$ \\ Matthew J Bair ${ }^{4}$ \\ Kurt Kroenke ${ }^{5}$ \\ Robert A Perera ${ }^{6}$ \\ Levent Dumenci ${ }^{7}$ \\ 'Departments of Physical \\ Therapy, Orthopaedic Surgery \\ and Rheumatology, Virginia \\ Commonwealth University, Richmond, \\ VA, USA; ${ }^{2}$ Department of Orthopaedic \\ Surgery, New York University Langone \\ Medical Center, New York, NY, USA; \\ ${ }^{3}$ Department of Rheumatology, Wake \\ Forest University School of Medicine, \\ Raleigh, NC, USA; ${ }^{4}$ Department of \\ Medicine, VA Center for Health \\ Information and Communication, \\ Indiana University School of Medicine, \\ Indianapolis, IN, USA; ${ }^{5}$ Department of \\ Medicine, Indiana University School \\ of Medicine, Indianapolis, IN, USA; \\ ${ }^{6}$ Department of Biostatistics, Virginia \\ Commonwealth University, Richmond, \\ VA, USA; ${ }^{7}$ College of Public Health, \\ Temple University, Philadelphia, PA, \\ USA
}

Correspondence: Daniel L Riddle Virginia Commonwealth University, Richmond, VA 23298-0224, USA

$\mathrm{Tel}+\mathrm{I} 8048280234$

Fax + I 8048288 III

Email dlriddle@vcu.edu
Background: Opioid use rates prior to knee arthroplasty (KA) among people who catastrophize about their pain are unknown. We determined prevalence of opioid use and compared patterns of preoperative opioid use and oral morphine equivalent (OME), a measure of daily opioid dose, across varied geographic sites. We also determined which baseline variables were associated with opioid use and OME.

Patients and methods: Preoperative opioid use data described type of opioid, dosage, and frequency among 397 patients scheduled for KA. Demographic, knee-related pain, and psychological distress dimensions were examined to identify variables associated with opioid use and opioid dose (OME). Opioid use prevalence and OME were compared across the four sites. A three-level censored regression determined variables associated with opioid use and OME. Results: The overall opioid use prevalence was $31.7 \%$ (95\% confidence interval $[\mathrm{CI}]=27.0$, $36.3)$ and varied across sites from $15.9 \%(95 \% \mathrm{CI}=9.0,22.8)$ to $51.2 \%(95 \% \mathrm{CI}=40.5,61.9)$. After adjustment, patients using opioids were more likely to be younger, African American, and have higher self-efficacy and comorbidity scores $(P<0.05)$. The only variable independently associated with OME was lower depressive symptoms $(P<0.05)$.

Conclusion: People who catastrophized prior to KA did not demonstrate increased preoperative opioid use based on current evidence, but variation in the prevalence of opioid use across study sites was substantial. Variables associated with opioid use were non-modifiable demographic and comorbidity variables.

Keywords: pain, catastrophizing, opioid, knee, arthroplasty

\section{Introduction}

Persistent opioid use by people with knee arthroplasty (KA) is a substantial problem that has received recent attention. ${ }^{1-4}$ Patients undergoing KA, for example, have the highest rate of postoperative opioid use among several of the more common major surgical procedures. ${ }^{2}$ The Centers for Disease Control and Prevention recently proposed guidelines for treating people with chronic pain, ${ }^{5}$ and the American Academy of Orthopaedic Surgeons (AAOS) has endorsed these recommendations. ${ }^{6}$ Chief among the guideline recommendations are that opioids should be used only when benefits in pain relief and function are expected to outweigh risks. Opioid-related risks in people with chronic pain have been highly publicized and include addiction, overdose, and death. ${ }^{7}$ Moreover, a recent systematic review ${ }^{8}$ and randomized clinical trial ${ }^{9}$ of opioids versus nonsteroidal anti-inflammatory drugs (NSAIDs) for people with chronic knee pain found that NSAIDs provided comparable pain relief to opioids. 
Among patients with knee osteoarthritis (OA) undergoing KA, the most powerful predictor of persistent opioid use is preoperative opioid use. ${ }^{3,10}$ An additional important predictor of persistent opioid use in people with chronic musculoskeletal pain ${ }^{11,12}$ is pain catastrophizing. ${ }^{3,13}$ Patients who catastrophize tend to ruminate about their pain, feel helpless by pain and magnify effects of pain on daily life. . $^{14,15}$

We recently recruited a multisite sample of patients scheduled for KA surgery who also had moderate to high levels of pain catastrophizing for a four-site randomized clinical trial of a Knee Arthroplasty Pain Coping Skills Training (KASTPain) trial. ${ }^{16}$ The overall purpose of the current investigation was to characterize the prevalence and type of preoperative opioid use in this unique KASTPain patient sample. Specifically, we estimated site-specific prevalence of opioid use among four clinical sites, the opioid morphine equivalent (OME) and variables associated with opioid use and OME. Because of the recent focus on the opioid use epidemic and importantly, methods to identify people at risk for opioid use, we focused on the rate of opioid use preoperatively, predictors of preoperative opioid use, and variation in the rate of opioid use across sites. Clinicians will likely benefit from knowing variables that associate with increased risk of preoperative opioid use and the extent to which opioid use varies across clinical sites. We hypothesized that the four sites would demonstrate varied opioid use but that overall, we would find a higher prevalence of opioid use as compared to the US literature-based historical control estimates of $25 \%-30 \%{ }^{3,17,18}$ because we studied individuals with moderate to high pain catastrophizing. We also hypothesized that a variety of modifiable, patient-level health variables would be associated with preoperative opioid use and dose after adjustment for non-modifiable variables.

\section{Patients and methods}

The study sample was taken from a three-arm randomized clinical trial with 1-year follow-up that examined effects of physical therapist-delivered pain coping skills relative to arthritis education or usual care for patients with at least moderate pain catastrophizing and scheduled for KA (the KASTPain study). The protocol for the trial has been published. ${ }^{16}$ Data collected were approved by the institutional review board (IRB) of the four participating sites (Virginia Commonwealth University, Duke University, Wake Forest University, and New York University). All subjects read and signed an IRB-approved consent form. While data were collected during a preoperative visit and at 2, 6, and 12 months post surgery, the focus of the current study was the baseline preoperative data.

\section{Study sample}

Participants had consented to KA prior to being screened for KASTPain. To be eligible, all participants were 45 years or older, passed a cognitive screen, ${ }^{19}$ had a diagnosis of knee $\mathrm{OA}$, and were scheduled for KA between 1 and 8 weeks following consent. Additionally, participants scored $\geq 16$ on the Pain Catastrophizing Scale (PCS) and $\geq 5$ on the Western Ontario and McMaster Universities Osteoarthritis Index (WOMAC) Pain scale. Scores of $\geq 16$ on the PCS indicate at least moderate pain catastrophizing, while scores of $\geq 5$ on the WOMAC Pain scale indicate at least minor function limiting pain. Exclusion criteria were revision or bilateral KA, inflammatory arthritis, fracture, malignancy or infection, or plans to undergo additional arthroplasty within 6 months of the index surgery.

The clinical trial was pragmatic by design in that we did not control the modes of analgesia, operative and pharmacologic pain management practices, or the perioperative surgical care at the participating sites. Controls would have artificially restricted variation in perioperative care and reduced generalizability of trial findings.

\section{Outcomes of interest - baseline opioid use and dose}

Following consent, study coordinators asked each participant to identify all medications taken specifically for knee pain from an extensive medication list. We focused on opioids specifically taken for knee pain because patients undergoing KA arthroplasty may be prescribed opioids for pain in other regions and the KA evidence has not specifically determined extent of opioid use for knee pain, the target of the KA intervention. ${ }^{3}$ Participants were categorized as either using or not using opioids. Evidence supports the validity of self-reported opioid use (yes or no) during in-person interviews. ${ }^{20,21}$ In addition to the type of opioid, participants indicated dosage and daily frequency of use for each opioid. Because patients may not accurately recall their opioid dosage, we reviewed the electronic medical record and recorded the medical record-based opioid dosage obtained from each participating site. Additionally, because some patients only take opioids as needed, we relied on participants' self-report of frequency as compared to prescribed frequencies documented in the medical record. We used self-reported opioid type, medical record-based dosage, and self-reported daily 
frequency to calculate the OME, reported in milligrams per day, as a measure of daily dose of opioid use..$^{22}$ The OME is calculated by multiplying dosage by daily frequency by a conversion factor for each opioid based on opioid strength. ${ }^{22}$

\section{Additional baseline variables}

The WOMAC Pain, Function, and Stiffness scales were used to quantify the extent of function limiting pain and difficulty with activity. WOMAC has strong psychometric properties for people with KA. ${ }^{23-25}$ Bodily pain location and severity were measured with a validated questionnaire. ${ }^{26}$ The bodily pain questionnaire asked the patient to identify which of 16 body regions had been painful for at least the prior 3 months. The previously validated Generalized Anxiety Disorder-7 (GAD-7) scale ${ }^{27}$ and the Patient Health Questionnaire-8 (PHQ-8) scale ${ }^{28}$ were used to quantify extent of anxiety and depressive symptoms, respectively. The eight-item Arthritis Self-Efficacy Scale is a validated measure of participants' beliefs in their abilities to control symptoms and functional challenges associated with arthritis. ${ }^{29}$ Comorbidity was quantified using a previously validated and modified Charlson Comorbidity Index. ${ }^{30}$ The PCS was used to measure pain catastrophizing. ${ }^{31}$ A substantial literature supports the psychometric properties of the $\mathrm{PCS}^{31,32}$ and the prognostic role of PCS scores in predicting poor outcome following KA. ${ }^{33-35}$ We conceptualized pain catastrophizing as minor, moderate, or severe based on approximate tertile distributions for the scale. Pain catastrophizing was considered as minor for scores of $0-15$ (not included in this study), moderate for scores of 16-29, and severe for scores of 30-52. For all scales, with one exception (i.e., Arthritis Self-Efficacy Scale), higher scores equated to worse results. Demographic measures included age, sex, race (African American or other), body mass index (BMI; $\mathrm{kg} / \mathrm{m}^{2}$ ), and current smoking status (Table 1 presents descriptive data and score ranges for each scale).

\section{Data analysis}

Descriptive statistics were used to summarize all baseline variables, while independent sample $t$-tests were used to compare continuous measures for opioid and non-opioid users. The chi-square statistic was applied to categorical variables. We used three-level, two-part regression analysis with a random intercept term to predict opioid use (yes or no) and oral morphine equivalent (OME).The analysis accounted for patients nested within surgeons and surgeons nested within site as well as the patients who did not report opioid use. Multilevel modeling accounts for differences in outcomes at both the surgeon and site levels so that any remaining associations
Table I Preoperative comparisons between patients taking opioids for knee pain and patients not taking opioids (total $n=$ 379)

\begin{tabular}{|c|c|c|c|}
\hline \multirow[t]{2}{*}{ Patient characteristics } & \multicolumn{2}{|l|}{ Opioid use } & \multirow[t]{2}{*}{$P$ value } \\
\hline & $\begin{array}{l}\text { Yes }(n= \\
120)\end{array}$ & $\begin{array}{l}\text { No }(n= \\
259)\end{array}$ & \\
\hline \multicolumn{4}{|l|}{ Demographics } \\
\hline Age (years) & $60.84(7.63)$ & $64.34(7.99)$ & $<0.00$ I \\
\hline Female (yes) & $32.8 \%$ & $29.4 \%$ & 0.50 \\
\hline BMI $\left(\mathrm{kg} / \mathrm{m}^{2}\right)$ & $33.27(6.11)$ & $31.69(6.19)$ & 0.022 \\
\hline African American (yes) & $46.3 \%$ & $23.7 \%$ & $<0.001$ \\
\hline Current smoker (yes) & $18.3 \%$ & $8.1 \%$ & 0.004 \\
\hline Total KA (yes) & $96.7 \%$ & $95 \%$ & 0.461 \\
\hline \multicolumn{4}{|l|}{ Knee-related health } \\
\hline WOMAC Pain (0-20) & $12.42(3.4 \mid)$ & $10.89(3.25)$ & $<0.001$ \\
\hline WOMAC Function (0-68) & $39.68(11.29)$ & 35.85 (11.49) & 0.003 \\
\hline WOMAC Stiffness (0-8) & $5.12(1.82)$ & $4.74(1.87)$ & 0.07 \\
\hline Knee pain duration (years) & II.43 (II.05) & $10.06(10.75)$ & 0.256 \\
\hline \multicolumn{4}{|l|}{ Overall health } \\
\hline Bodily pain score $(0-16)$ & $6.83(4.43)$ & $5.02(3.72)$ & $<0.001$ \\
\hline Comorbidity score (0-45) & $10.43(4.60)$ & $7.82(3.54)$ & $<0.001$ \\
\hline \multicolumn{4}{|l|}{ Psychological health } \\
\hline GAD-7 (0-2I) & $6.66(5.34)$ & $4.7 I(4.60)$ & $<0.001$ \\
\hline $\begin{array}{l}\text { PHQ-8 depressive } \\
\text { symptoms }(0-24)\end{array}$ & $7.19(5.32)$ & $5.25(4.56)$ & $<0.001$ \\
\hline $\begin{array}{l}\text { PCS pain catastrophizing } \\
(0-52)\end{array}$ & $31.10(9.54)$ & $29.29(9.12)$ & 0.078 \\
\hline Self-efficacy (8-80) & $48.40(18.30)$ & $49.81(17.63)$ & 0.476 \\
\hline
\end{tabular}

Notes: Data are presented as mean (SD) or percent. Independent sample $t$-tests were conducted on continuous variables and $\chi^{2}$ tests were applied to categorical variables.

Abbreviations: BMI, body mass index; KA, knee arthroplasty; WOMAC, Western Ontario and McMaster Universities Osteoarthritis Index; GAD-7, Generalized Anxiety Disorder-7; PHQ-8, Patient Health Questionnaire-8; PCS, Pain Catastrophizing Scale.

cannot be attributed to surgeon or site but rather the predictor variables of interest. Two regression equations were estimated from the set of predictors based on prior evidence linking these predictors with opioid use. , $^{3,1736}$ In the first equation, the outcome was binary (opioid user versus nonuser). In the second equation, the magnitude of OME was estimated from the predictors among those who had nonzero OME values. For the OME equation, outcome was censored below an OME score of 1 because many patients did not take opioids, leading to an accumulation of zeros in the outcome distribution. The two-step procedure described by Kapitula was used to estimate all model parameters. ${ }^{37}$ All analyses were conducted using SAS software, Version 9.4 of the SAS System for Windows, Copyright @2016 (SAS Institute Inc., Cary, NC, USA).

\section{Results}

A total of 397 participants from four sites provided consent, and of these patients, 18 had their surgery canceled, while 379 underwent KA. Of these patients, 362 had total KA, 
while 17 underwent unicompartmental KA. The average age of participants was 63.2 years; $35.4 \%$ self-reported as African American and 66.8\% were females. Self-reported knee pain duration ranged from a minimum of 5 months to a maximum of 58 years. Because of substantially skewed pain duration data, the median pain duration was 6 years (first quartile $=3$ years, third quartile $=15$ years). This duration of knee pain is typical of people undergoing KA and is consistent with definitions of chronic pain ( $>3$ months).$^{38}$ People using opioids for knee pain were younger $(P<0.001)$, more likely to be African American $(P<0.001)$, and reported worse WOMAC Pain score $(P<0.001)$ and Function score $(P=0.003)$, greater comorbidity scores $(P<0.001)$, more bodily pain areas $(P<0.001)$, and worse anxiety and depressive symptoms $(P<0.001)$. The characteristics of those using opioids and those not using opioids are summarized in Table 1. The correlation matrix of psychological distress, WOMAC, comorbidity, and bodily pain site measures is given in Table 2. As expected, the association between WOMAC Pain and Function measures was high $(r=0.72)$ as was the association between anxiety and depressive symptoms $(r=0.70)$. The remaining associations were in the low to moderate range. A variety of different types, dosages, and frequencies of daily opioid use were reported, and these are summarized in Table 3.

\section{Prevalence of preoperative opioid use and opioid dose across the four sites}

The overall proportion of opioid use was $31.7 \%$ (95\% confidence interval $[\mathrm{CI}]=27.0,36.3)$. The prevalence of opioid use among those with unicompartmental versus total KA was not significantly different $\left(\chi^{2}=0.54, P=0.47\right)$. The proportion of opioid users ranged from $15.9 \%(95 \% \mathrm{CI}=9.0,22.8)$ for Site 4 to $51.2 \%(95 \% \mathrm{CI}=40.5,61.9)$ for Site 1 (Figure 1$)$. Of the 120 patients who self-reported opioid use, OME data were available for 110 patients. Because of skewed OME data, we report medians. For the entire sample, median OME was $22.5 \mathrm{mg}$ /day. The median OME potency per site ranged from 15 to $30 \mathrm{mg} /$ day (Table 3 ).

\section{Baseline variables associated with opioid use}

After accounting for patients nested within surgeon and surgeons nested within site, younger age $(P=0.01)$, African American race $(P=0.02)$, higher self-efficacy $(P=$ $0.02)$, and higher comorbidity score $(P<0.001)$ increased the probability of opioid use (Table 4 ). Odds ratios were reported such that, for example, for every point increase in the comorbidity score, odds of using an opioid increased, on average, by $14.5 \%$. The parameter estimate for age was coded as negative, which indicates that, on average, for every year increase in age, opioid use decreased by $4.5 \%$. Psychological distress variables, number of bodily pain sites, and WOMAC Pain scores were not associated $(P>0.05)$ with opioid use after adjusting for the other variables in the model (Table 4).

Table 3 Summary of opioid type, dosage, and frequency for 120 patients taking opioids

\begin{tabular}{llll}
\hline Category & $\mathbf{n}(\%)$ & $\begin{array}{l}\text { Median } \\
\text { milligram } \\
\text { dosage } \\
\text { (range) }\end{array}$ & $\begin{array}{l}\text { Median } \\
\text { daily } \\
\text { frequency } \\
\text { (range) }\end{array}$ \\
\hline Codeine with acetaminophen & $5(4.17)$ & $30(5-30)$ & $1(1-4)$ \\
Hydrocodone & $34(28.33)$ & $7.5(1-30)$ & $2(1-6)$ \\
Morphine & $3(2.5)$ & $15(5-50)$ & $3(2-3)$ \\
Oxycodone & $44(36.67)$ & $5(5-50)$ & $2(1-4)$ \\
Tramadol & $48(40.0)$ & $50(10-100)$ & $2(1-6)$ \\
Methadone & $3(2.5)$ & $10(10-20)$ & $3(2-4)$ \\
Others & $3(2.5)$ & - & - \\
\hline Nete: $^{\mathrm{a}}$ & &
\end{tabular}

Note: aHydromorphone, tapentadol, and fentanyl patch.

Table 2 Correlation matrix for the psychological health, comorbidity, WOMAC, and bodily pain site scores ${ }^{\mathrm{a}}$

\begin{tabular}{|c|c|c|c|c|c|c|c|c|}
\hline & PCS & GAD-7 & PHQ-8 & Self-efficacy & Comorbidity & WOMAC Pain & $\begin{array}{l}\text { WOMAC } \\
\text { Stiffness }\end{array}$ & $\begin{array}{l}\text { WOMAC } \\
\text { Function }\end{array}$ \\
\hline GAD-7 & 0.307 & & & & & & & \\
\hline PHQ-8 & 0.266 & 0.702 & & & & & & \\
\hline Self-efficacy & -0.208 & $-0.34 I$ & -0.372 & & & & & \\
\hline Comorbidity & 0.182 & 0.314 & 0.355 & -0.236 & & & & \\
\hline WOMAC Pain & 0.429 & 0.256 & 0.292 & -0.252 & 0.284 & & & \\
\hline WOMAC Stiffness & 0.159 & 0.158 & 0.213 & -0.210 & 0.183 & 0.451 & & \\
\hline WOMAC Function & 0.393 & 0.283 & $0.35 I$ & -0.260 & 0.315 & 0.724 & 0.510 & \\
\hline Bodily pain & 0.162 & 0.340 & 0.335 & -0.220 & 0.408 & 0.340 & 0.291 & 0.326 \\
\hline
\end{tabular}

Note: aAll coefficients are significantly different from 0 at the $P<0.01$ level.

Abbreviations: WOMAC, Western Ontario and McMaster Universities Osteoarthritis Index; PCS, Pain Catastrophizing Scale; GAD-7, Generalized Anxiety Disorder-7; PHQ-8, Patient Health Questionnaire-8. 


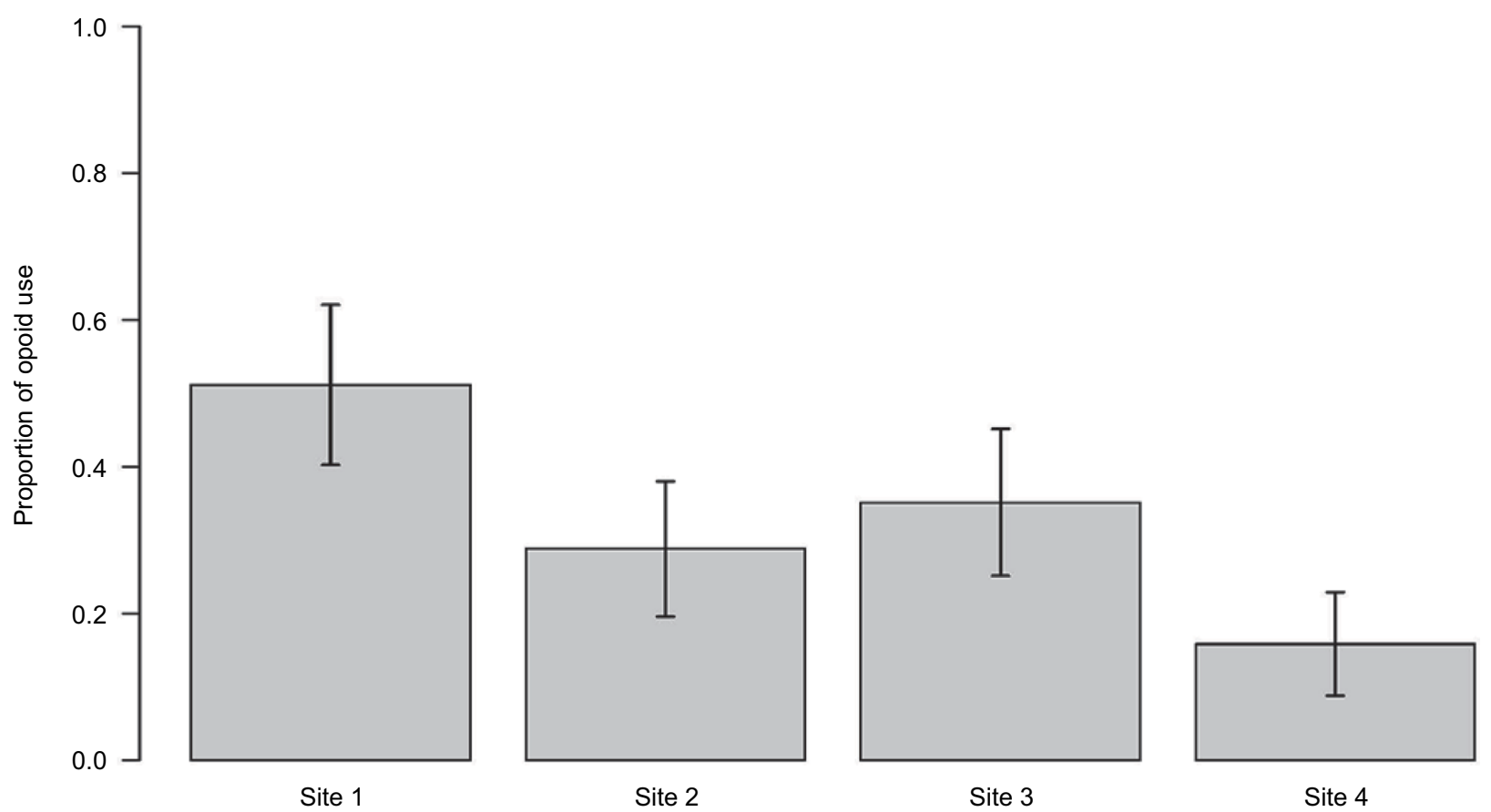

Figure I Proportion (with 95\% Cls) of patients at each of four sites who reported taking opioids for their knee pain prior to surgery. Abbreviation: $\mathrm{Cl}$, confidence interval.

Table 4 Results of regression models of variables associated with either opioid use or OME

\begin{tabular}{|c|c|c|c|c|c|}
\hline Model and variables & $\begin{array}{l}\text { Regression } \\
\text { parameter }\end{array}$ & SE & $t$ value & $\mathbf{P}$ & Odds ratio $(\mathrm{Cl})$ \\
\hline \multicolumn{6}{|l|}{ Opioid use (yes or no) } \\
\hline Intercept & -1.630 & 1.582 & -1.03 & 0.379 & \\
\hline Pain catastrophizing (PCS) & -0.016 & 0.016 & -0.99 & 0.324 & $0.985(0.954,1.016)$ \\
\hline Depressive symptoms (PHQ-8) & 0.015 & 0.037 & 0.42 & 0.672 & $1.016(0.954,1.092)$ \\
\hline Self-efficacy scale & 0.020 & 0.008 & 2.43 & 0.016 & $1.020(1.004,1.037)$ \\
\hline Bodily pain sites & 0.022 & 0.036 & 0.61 & 0.543 & $1.022(0.953,1.096)$ \\
\hline Anxiety symptoms (GAD-7) & 0.037 & 0.037 & 0.97 & 0.332 & $\mathrm{I} .037(0.963, \mathrm{I} .096)$ \\
\hline Comorbidity score (modified Charlson) & 0.136 & 0.036 & 3.81 & $<0.001$ & $1.145(1.068,1.228)$ \\
\hline Knee pain (WOMAC Pain) & 0.077 & 0.045 & 1.72 & 0.086 & $1.080(0.989,1.180)$ \\
\hline Age (years) & -0.046 & 0.018 & -2.58 & 0.010 & $0.955(0.922,0.989)$ \\
\hline Race (African American) & 0.621 & 0.275 & 2.26 & 0.024 & $1.862(1.085,3.195)$ \\
\hline $\mathrm{BMI}$ & 0.012 & 0.022 & 0.56 & 0.576 & $1.012(0.970,1.057)$ \\
\hline Sex (female) & 0.072 & 0.279 & 0.26 & 0.798 & $1.074(0.620,1.861)$ \\
\hline \multicolumn{6}{|l|}{ OME } \\
\hline Intercept & 51.583 & 59.078 & 0.87 & 0.447 & \\
\hline Pain catastrophizing (PCS) & 0.005 & 0.528 & 0.01 & 0.993 & \\
\hline Depressive symptoms (PHQ-8) & -2.635 & 1.190 & -2.22 & 0.030 & \\
\hline Self-efficacy & -0.151 & 0.280 & -0.54 & 0.590 & \\
\hline Bodily pain sites & 1.569 & 1.039 & 1.51 & 0.135 & \\
\hline Anxiety symptoms (GAD-7) & 0.735 & 1227 & 0.60 & 0.552 & \\
\hline Comorbidity score & -0.452 & 1.233 & -0.37 & 0.715 & \\
\hline Knee pain (WOMAC Pain) & 1.419 & 1.450 & 0.98 & 0.331 & \\
\hline Age (years) & -0.302 & 0.615 & -0.49 & 0.625 & \\
\hline Race (African American) & 3.518 & 8.980 & 0.39 & 0.696 & \\
\hline $\mathrm{BMI}$ & 0.067 & 0.751 & 0.09 & 0.929 & \\
\hline Sex (female) & -4.430 & 9.435 & -0.47 & 0.640 & \\
\hline
\end{tabular}

Abbreviations: OME, oral morphine equivalent; SE, standard error; Cl, confidence interval; PCS, Pain Catastrophizing Scale; PHQ-8, Patient Health Questionnaire-8; GAD-7, Generalized Anxiety Disorder-7; WOMAC, Western Ontario and McMaster Universities Osteoarthritis Index; BMI, body mass index. 


\section{Baseline variables associated with OME}

After accounting for patients nested within surgeon and surgeons nested within site, the only variable associated with OME was lower depressive symptoms $(P=0.030)$. For every point increase in the PHQ-8 depressive symptoms score, OME decreased by $2.6 \mathrm{mg}$ after adjusting for all other variables in the model.

\section{Discussion}

Several guidelines for the treatment of knee OA exist including those developed by the $\mathrm{AAOS}^{39}$ and the American College of Rheumatology (ACR). ${ }^{40}$ These guidelines do not recommend the routine use of opioids for the treatment of knee OA, and the ACR recommends that they should be used only for patients deemed not to be surgical candidates. In addition, opioids have been shown to be no more effective than NSAIDs for the treatment of knee OA. ${ }^{8}$ Highlighting the potential overuse of these medications, the Surgeon General sent a letter in 2016 to every physician in America calling for clinicians to receive education on how to treat pain safely and effectively to positively impact the opioid epidemic. ${ }^{41}$

Consensus-based recommendations for the use of opioids are generally vague. The lack of clarity of definitions for whom opioids should be prescribed combined with a lack of clinician training likely leads to substantial variation in opioid prescribing not only for pain associated with knee OA as we found, but also for many other pain conditions. ${ }^{42}$ For patients scheduled for KA, an opioid use rate of $\sim 30 \%$ has been consistently reported and was supported in our study. Whether an opioid use rate of $30 \%$ represents overuse, underuse, or appropriate use cannot be determined from our study or from current evidence. However, the substantial variation across the four sites with opioid use rates ranging from $15.9 \%$ to $51.2 \%$ suggests that there is likely inappropriate use of opioids by some patients. This variation occurred despite only subtle and inconsistent differences across sites in mean preoperative WOMAC Pain and Function scores as well as minimal variation in depressive symptom and pain catastrophizing scores (Table 5). While some of these differences were statistically significant, these small differences, in our view, are not clinically important. These data suggest that between-site differences in pain, function, and psychological distress likely did not contribute to variation in opioid use. Given the lack of benefit of opioids over and above that of NSAIDs, ${ }^{8,9}$ combined with risks associated with persistent opioid use, ${ }^{7}$ we suspect that opioid overuse is more common and more consequential than opioid underuse in this population, but more research is needed to test this hypothesis.

Site-specific differences in opioid use rates may be related to a variety of factors including variations at the person-level (eg., age and sex $){ }^{43}$ hospital system level ${ }^{43}$ physician group practice, and state-to-state differences across sites. ${ }^{44}$ The institutional culture of Site 1, for example, may have been more lenient or more prone toward opioid use as compared to that of Site 4 regarding opioid use among these types of patients. While our study was not designed or powered to identify factors that explained this variation, these site-related differences provide impetus for studies of geographically based variation in opioids prescribed in KA with a focus on identification of patient-, clinician-, and system-level factors influencing opioid use.

Our study has several additional key findings. Contrary to our hypothesis, the prevalence of opioid use was not higher in our sample of patients with moderate to high pain catastrophizing as compared to heterogeneous samples of patients undergoing KA. ${ }^{3,17,18}$ Given that patients who catastrophize are psychologically distressed and feel hopeless about their pain, it is encouraging that higher opioid use was not seen in our sample as compared to more heterogeneous KA cohorts. The OME also was relatively low across the four sites and suggests that high-dose opioid use is relatively uncommon in this population.

Prior evidence on patients scheduled for KA did not specify details of opioid type and dose or the extent of variation across sites or geographic regions. Pain in other areas of the body is common in $\mathrm{KA},{ }^{45,46}$ and current evidence also does not characterize whether opioids were used for knee pain versus other bodily pain. In addition, only one study reported OME, ${ }^{3}$ an indicator of opioid dose and a predictor of persistent use. ${ }^{3,22}$

Our hypothesis regarding patient-level, modifiable risk factors of opioid use and dosage was not supported.

Table 5 Preoperative WOMAC, PHQ-8, and PCS scores stratified by site

\begin{tabular}{lllll}
\hline & Site I, mean (SD) & Site 2, mean (SD) & Site 3, mean (SD) & Site 4, mean (SD) \\
\hline WOMAC Pain* & $12.4(3.3)$ & $10.3(3.2)$ & $11.4(3.5)$ & $11.5(3.3)$ \\
WOMAC Function* & $37.8(11.3)$ & $32.7(11.9)$ & $39.0(11.1)$ & $38.8(10.9)$ \\
PHQ-8 & $6.8(5.0)$ & $4.6(3.9)$ & $6.3(5.4)$ & $5.9(5.0)$ \\
Pain catastrophizing* & $31.6(9.1)$ & $26.7(8.6)$ & $30.8(9.7)$ & $30.5(9.1)$ \\
\hline
\end{tabular}

Note: $* P<0.01$ using analysis of variance with correction for multiple comparisons.

Abbreviations: WOMAC, Western Ontario and McMaster Universities Osteoarthritis Index; PHQ-8, Patient Health Questionnaire-8; PCS, Pain Catastrophizing Scale. 
Potentially modifiable psychological distress variables, number of bodily pain sites, and WOMAC Pain scores were not associated with either opioid use or dosage. Identification of variables and particularly modifiable variables associated with opioid use or dose prior to KA may facilitate the development and testing of interventions to reduce opioid use prior to KA and subsequently reduce persistent opioid risks and improve outcomes. Given that KA surgery is effective at substantially reducing knee pain in $\sim 80 \%$ of patients, ${ }^{47}$ persistent opioid use following KA should be uncommon. Goesling et $\mathrm{al}^{3}$ reported that $\sim 15 \%$ of KA patients were taking opioids 6 months following surgery, and of these patients, two-thirds were taking opioids prior to surgery. KA appears to provide a window of opportunity for reduction of persistent opioid usage. Interventions designed to reduce opioid use appear to have strong potential, ${ }^{4}$ although more research is needed to inform these approaches.

In our study, preoperative opioid use was independently associated with younger age, African-American race, higher comorbidity scores, and higher self-efficacy. Patients with higher self-efficacy scores reported having more control of their OA symptoms and also were more likely to use opioids. Higher opioid use among those with higher self-efficacy may be driven, at least somewhat, by patients who express confidence in their ability to control their pain via opioids, although more research is needed to test this hypothesis.

While we were unable to identify modifiable factors associated with opioid use, clinicians may benefit from recognizing which patients may be at greater risk for opioid use, such as those who are African American and younger and those with multiple comorbidities. Raising clinician awareness of the demographic subgroups at risk for opioid use may reduce overprescribing to these subgroups. The challenges, particularly among these higher use subgroups, are to identify patients in whom benefits from opioid use outweigh risks and patients most likely to be at risk for persistent opioid use when risks may outweigh the benefits of opioid treatment and to determine the optimal protocol each patient should use.

The only variable associated with opioid dose, as measured by OME, was lower depressive symptom scores. This was an unexpected finding and, to our knowledge, has not been reported previously. Patients with lower levels of depressive symptoms may advocate for higher doses of opioids or clinicians may be sensitive to people with higher levels of depressive symptoms and are less likely to prescribe higher doses to these patients. Alternatively, pain control afforded by opioids may impact depressive symptoms in a positive way. More research is needed to corroborate and further explore these findings.

Our study had a number of strengths and limitations. The major limitation was our cross-sectional study design, but, to our knowledge, ours is the first to report site-specific variation in opioid use among patients scheduled for KA. Additionally, while the study sites were located in the southern and northeast US, our study does not inform the extent of variation in opioid use in other parts of the US. Our study also examined only university-based practice settings. Future work should examine opioid use variation in more geographic areas and other practice settings, similar to the work of McDonald et al. ${ }^{42}$ A strength of our study is that it is the first to report opioid use specifically for knee pain. However, because we did not collect opioid use data for other pain sources and locations, our estimates may underestimate overall opioid use. Additionally, although we relied on a combination of self-report and medical record review to confirm opioid use, dosage, and frequency, we did not perform urinary biomarker analysis to confirm usage. Finally, we recruited people with moderate to high levels of pain catastrophizing. Results may not generalize to people with either no pain catastrophizing or low levels of pain catastrophizing.

\section{Conclusion}

People who catastrophize about their pain prior to KA did not demonstrate significantly increased opioid use compared with estimates from heterogeneous KA samples previously studied. However, variation in the prevalence of opioid use across study sites was substantial. Patients at a greater risk of preoperative opioid use had a higher comorbidity burden, were younger, and more likely to be African American. While opioid dosage was relatively low, the prevalence of preoperative opioid use was relatively high, providing the opportunity to develop strategies to lower preoperative opioid use in this population. Future research exploring the appropriate use of opioids in patients with pain catastrophizing before KA is needed.

\section{Significance}

Patients who catastrophize about their pain prior to KA demonstrate opioid use rates that are similar to those of people undergoing KA in heterogeneous samples. Variation in opioid use rates is highly dependent on clinical site.

\section{Acknowledgments}

We wish to thank all study staff for the participation and professionalism, and most importantly, we wish to thank 
the patients for their willingness to participate in the study. The study was supported by a grant (UM1AR062800) from the National Institute of Arthritis and Musculoskeletal and Skin Diseases (NIAMS) of the National Institutes of Health (NIH). Support was also provided by an NIH CTSA grant (UL1TR000058) from the National Center for Advancing Translational Sciences of Virginia Commonwealth University. The content is solely the responsibility of the authors and does not necessarily represent the official views of the NIH.

\section{Disclosure}

The authors report no conflicts of interest in this work.

\section{References}

1. Zarling BJ, Yokhana SS, Herzog DT, Markel DC. Preoperative and postoperative opiate use by the arthroplasty patient. J Arthroplasty. 2016;31(10):2081-2084.

2. Sun EC, Darnall B, Baker LC, Mackey S. Incidence of and risk factors for chronic opioid use among opioid-naive patients in the postoperative period. JAMA Intern Med. 2016;176(9):1286-1293.

3. Goesling J, Moser SE, Zaidi B, et al. Trends and predictors of opioid use after total knee and total hip arthroplasty. Pain. 2016;157(6):1259-1265.

4. Nguyen LC, Sing DC, Bozic KJ. Preoperative reduction of opioid use before total joint arthroplasty. J Arthroplasty. 2016;31(9 suppl):282-287.

5. Dowell D, Haegerich TM, Chou R. CDC guideline for prescribing opioids for chronic pain - United States, 2016. JAMA. 2016;315(15): 1624-1645.

6. Teuscher D. Docket No. CDC-2015-0112 - CDC Guideline for Prescribing Opioids for Chronic Pain (Guideline). Available from: https://www. cdc.gov/drugoverdose/prescribing/guideline.html. Accessed July 14, 2017.

7. Kaplovitch E, Gomes T, Camacho X, Dhalla IA, Mamdani MM, Juurlink DN. Sex differences in dose escalation and overdose death during chronic opioid therapy: a population-based cohort study. PLoS One. 2015;10(8): 0134550

8. Smith SR, Deshpande BR, Collins JE, Katz JN, Losina E. Comparative pain reduction of oral non-steroidal anti-inflammatory drugs and opioids for knee osteoarthritis: systematic analytic review. Osteoarthritis Cartilage. 2016;24(6):962-972.

9. Krebs EE, Gravely A, Nugent S, et al. Effect of opioid vs nonopioid medications on pain-related function in patients with chronic back pain or hip or knee osteoarthritis pain: the SPACE randomized clinical trial. JAMA. 2018;319(9):872-882.

10. Inacio MC, Hansen C, Pratt NL, Graves SE, Roughead EE. Risk factors for persistent and new chronic opioid use in patients undergoing total hip arthroplasty: a retrospective cohort study. BMJ Open. 2016;6(4):e010664.

11. Arteta J, Cobos B, Hu Y, Jordan K, Howard K. Evaluation of how depression and anxiety mediate the relationship between pain catastrophizing and prescription opioid misuse in a chronic pain population. Pain Med. 2015;17(2):295-303.

12. Martel MO, Wasan AD, Jamison RN, Edwards RR. Catastrophic thinking and increased risk for prescription opioid misuse in patients with chronic pain. Drug Alcohol Depend. 2013;132(1-2):335-341.

13. Valdes AM, Warner SC, Harvey HL, et al. Use of prescription analgesic medication and pain catastrophizing after total joint replacement surgery. Semin Arthritis Rheum. 2015;45(2):150-155.

14. Turner JA, Aaron LA. Pain-related catastrophizing: what is it? Clin J Pain. 2001;17(1):65-71.
15. Sullivan MJ, Thorn B, Haythornthwaite JA, et al. Theoretical perspectives on the relation between catastrophizing and pain. Clin J Pain. 2001;17(1):52-64.

16. Riddle DL, Keefe FJ, Ang D, et al. A phase iii randomized three-arm trial of physical therapist delivered pain coping skills training for patients with total knee arthroplasty: the kastpain protocol. BMC Musculoskelet Disord. 2012;13(1):149.

17. Franklin PD, Karbassi JA, Li W, Yang W, Ayers DC. Reduction in narcotic use after primary total knee arthroplasty and association with patient pain relief and satisfaction. J Arthroplasty. 2010;25(6 suppl):12-16.

18. Rakel BA, Zimmerman MB, Geasland K, et al. Transcutaneous electrical nerve stimulation for the control of pain during rehabilitation after total knee arthroplasty: a randomized, blinded, placebo-controlled trial. Pain. 2014;155(12):2599-2611.

19. Callahan CM, Unverzagt FW, Hui SL, Perkins AJ, Hendrie HC. Six-item screener to identify cognitive impairment among potential subjects for clinical research. Med Care. 2002;40(9):771-781.

20. Pit S, Byles J. Older Australians' medication use: self-report by phone showed good agreement and accuracy compared with home visit. JClin Epidemiol. 2010;63(4):428-434.

21. Lacasse A, Ware MA, Bourgault P, et al. Accuracy of self-reported prescribed analgesic medication use: linkage between the Quebec pain registry and the Quebec administrative prescription claims databases. Clin J Pain. 2016;32(2):95-102.

22. Nielsen S, Degenhardt L, Hoban B, Gisev N. A synthesis of oral morphine equivalents (OME) for opioid utilisation studies. Pharmacoepidemiol Drug Saf. 2016;25(6):733-737.

23. Escobar A, Quintana JM, Bilbao A, Arostegui I, Lafuente I, Vidaurreta I. Responsiveness and clinically important differences for the WOMAC and SF-36 after total knee replacement. Osteoarthritis Cartilage. 2007;15(3):273-280.

24. Escobar A, Garcia PL, Herrera-Espineira C, et al. Total knee replacement; minimal clinically important differences and responders. Osteoarthritis Cartilage. 2013;21(12):2006-2012.

25. Escobar A, Riddle DL. Concordance between important change and acceptable symptom state following knee arthroplasty: the role of baseline scores. Osteoarthritis Cartilage. 2014;22(8):1107-1110.

26. Arnold LM, Stanford SB, Welge JA, Crofford LJ. Development and testing of the fibromyalgia diagnostic screen for primary care. JWomens Health (Larchmt). 2012;21(2):231-239.

27. Spitzer RL, Kroenke K, Williams JB, Lowe B. A brief measure for assessing generalized anxiety disorder: the GAD-7. Arch Intern Med. 2006;166(10):1092-1097.

28. Kroenke K, Spitzer RL, Williams JB. The PHQ-9: validity of a brief depression severity measure. J Gen Intern Med. 2001;16(9):606-613.

29. Mueller A, Hartmann M, Mueller K, Eich W. Validation of the arthritis self-efficacy short-form scale in German fibromyalgia patients. Eur $J$ Pain. 2003;7(2):163-171.

30. Sangha O, Stucki G, Liang MH, Fossel AH, Katz JN. The selfadministered comorbidity questionnaire: a new method to assess comorbidity for clinical and health services research. Arthritis Rheum. 2003;49(2):156-163.

31. Sullivan MJL, Bishop S, Pivik J. The pain catastrophizing scale: development and validation. Psych Assessment. 1995;7(4):524-532.

32. Turner JA, Mancl L, Aaron LA. Pain-related catastrophizing: a daily process study. Pain. 2004;110(1-2):103-111.

33. Vissers MM, Bussmann JB, Verhaar JA, Busschbach JJ, Bierma-Zeinstra SM, Reijman M. Psychological factors affecting the outcome of total hip and knee arthroplasty: a systematic review. Semin Arthritis Rheum. 2012;41(4):576-588.

34. Sullivan M, Tanzer M, Stanish W, et al. Psychological determinants of problematic outcomes following total knee arthroplasty. Pain. 2009;143(1-2):123-129.

35. Riddle DL, Wade JB, Jiranek WA, Kong X. Preoperative pain catastrophizing predicts pain outcome after knee arthroplasty. Clin Orthop Relat Res. 2009;468(3):798-806. 
36. Banka TR, Ruel A, Fields K, YaDeau J, Westrich G. Preoperative predictors of postoperative opioid usage, pain scores, and referral to a pain management service in total knee arthroplasty. HSS J. 2015;11(1):71-75.

37. Kapitula LR. When Two Are Better Than One: Fitting Two-Part Models Using $S A S \circledR$. Available from: https://support.sas.com/resources/papers/ proceedings15/3600-2015.pdf Accessed November 10, 2016.

38. Merskey H, Bogduk N. Classification of Chronic Pain. Descriptions of Chronic Pain Syndromes and Definitions of Pain Terms. 2nd ed. Seattle: IASP Press; 1994.

39. American Academy of Orthopaedic Surgeons. Treatment of Osteoarthritis of the Knee. Evidence-based Guideline. 2nd ed. Available from http://www.aaos.org/research/guidelines/TreatmentofOsteoarthritisoftheKneeGuideline.pdf Accessed June 25, 2017.

40. Hochberg MC, Altman RD, April KT, et al; American College of Rheumatology. American college of rheumatology 2012 recommendations for the use of nonpharmacologic and pharmacologic therapies in osteoarthritis of the hand, hip, and knee. Arthritis Care Res (Hoboken). 2012;64(4):465-474.

41. Murthy VH [homepage on the Internet]. Letter from the Surgeon General. Available from: http://turnthetiderx.org/ Accessed December 30, 2017.
42. McDonald DC, Carlson K, Izrael D. Geographic variation in opioid prescribing in the U.S. J Pain. 2012;13(10):988-996.

43. Morgan SG, Cunningham CM, Hanley GE. Individual and contextual determinants of regional variation in prescription drug use: an analysis of administrative data from British Columbia. PLoS One. 2010;5(12):e15883.

44. Morden NE, Munson JC, Colla CH, et al. Prescription opioid use among disabled Medicare beneficiaries: intensity, trends, and regional variation. Med Care. 2014;52(9):852-859.

45. Perruccio AV, Power JD, Evans HM, et al. Multiple joint involvement in total knee replacement for osteoarthritis: effects on patient-reported outcomes. Arthritis Care Res (Hoboken). 2012;64(6):838-846.

46. Ayers DC, Li W, Oatis C, Rosal MC, Franklin PD. Patient-reported outcomes after total knee replacement vary on the basis of preoperative coexisting disease in the lumbar spine and other nonoperatively treated joints: the need for a musculoskeletal comorbidity index. J Bone Joint Surg Am. 2013;95(20):1833-1837.

47. Beswick AD, Wylde V, Gooberman-Hill R, Blom A, Dieppe P. What proportion of patients report long-term pain after total hip or knee replacement for osteoarthritis? A systematic review of prospective studies in unselected patients. BMJ Open. 2012;2(1):e000435.
Journal of Pain Research

\section{Publish your work in this journal}

The Journal of Pain Research is an international, peer reviewed, open access, online journal that welcomes laboratory and clinical findings in the fields of pain research and the prevention and management of pain. Original research, reviews, symposium reports, hypothesis formation and commentaries are all considered for publication.

\section{Dovepress}

The manuscript management system is completely online and includes a very quick and fair peer-review system, which is all easy to use. Visit http://www.dovepress.com/testimonials.php to read real quotes from published authors. 